\title{
PMP22 related congenital hypomyelination neuropathy
}

G M Fabrizi, A Simonati, F Taioli, T Cavallaro, M Ferrarini, F Rigatelli, A Pini, M L Mostacciuolo, N Rizzuto

\begin{abstract}
The peripheral myelin protein 22 (PMP22) is a tetraspan membrane protein which is localised in the compact myelin of the peripheral nerves. In fibroblasts, where it was originally identified as growth arrest related factor 3 (Gas3), PMP22 has been shown to modulate cell proliferation; in the peripheral nervous system its roles are still debated. The duplication of PMP22 is the most common cause of the demyelinating form of the autosomal dominant Charcot-MarieTooth neuropathy (CMT1A); rarer missense mutations of PMP22 also cause CMT1A or severe dehypomyelinating neuropathies of infancy grouped under the heading of Dejerine-Sottas syndrome (DSS). Here, a sporadic patient affected with DSS is described; nerve biopsy disclosed a picture of hypomyelination/ amyelination with basal laminae onion bulbs and no florid demyelination and it was consistent with congenital hypomyelination neuropathy (CHN); molecular analysis disclosed a novel point mutation of PMP22 that causes a non-conservative arginine for cysteine substitution at codon 109 , in the third transmembrane domain. $\mathrm{CHN}$ is the rarest and severest form of DSS and it is thought to reflect dysmyelination rather than demyelination. The reported case suggests that missense point mutations may alter a putative role of PMP22 in modulating Schwann cell growth and differentiation.

(F Neurol Neurosurg Psychiatry 2001;70:123-126)
\end{abstract}

Keywords: Dejerine-Sottas syndrome; congenital hypomyelination neuropathy; PMP22

The peripheral myelin protein 22 (PMP22) is a tetraspan membrane glycoprotein expressed in myelinating Schwann cells as well as in other neural and non-neural tissues. In fibroblasts, it plays a part in the regulation of the cell cycle. In peripheral nerves, PMP22 localises in the compact myelin, accounts for $2 \%-5 \%$ of the total myelin proteins, and has a still unclear function. ${ }^{1}$ PMP22 has four transmembrane domains (TM1-4), two short cytoplasmic tails, a short intracellular loop, and two extracellular loops; the first loop bears the carbohydrate epitope L2/HNK1, a mediator of adhesive processes. ${ }^{1}$

The heterozygous 1.5 megabases $(\mathrm{Mb})$ duplication at chromosome 17p11.2-p12 which encompasses PMP22 causes the autosomal dominant Charcot-Marie-Tooth neuropathy type 1A (CMT1A), characterised by decreased nerve conduction velocities (NCVs) and a well known picture of deremyelination with onion bulbs. Very rare heterozygous missense point mutations that affect one of the four TMs of PMP22 also cause dominant or sporadic forms of CMT1A or severer neuropathies of infancy characterised by extremely decreased NCVs and by dehypomyelination ${ }^{2}$; the last are still classified as Dejerine-Sottas syndrome (DSS) ${ }^{2-3}$ although DSS was long considered to be strictly autosomal recessive. ${ }^{4}$ The histopathology of missense mutations is poorly characterised. The $1.5 \mathrm{Mb}$ deletion at chromosome 17p11.2-p12 and rare nonsense mutations cause the mild hereditary neuropathy with liability to pressure (HNPP) which is associated with the pathological phenotype of tomaculous neuropathy. ${ }^{2}$

Here, we describe a sporadic patient harbouring a novel heterozygous Cys109Arg substitution of PMP22 associated with congenital hypomyelination neuropathy $(\mathrm{CHN})$, the rarest and severest form of DSS. ${ }^{4}$

\section{Case report}

Our patient, a 14 year old girl, is the first child of healthy non-consanguineous parents; her 12 year old brother is healthy. Early motor milestones were delayed: she could sit at 9 months and walk with orthoses at 4 years. At the age of 3 years she could neither stand nor walk unaided; there were generalised hypotonia and weakness, mainly of the legs, and areflexia. At the median nerve, motor nerve conduction velocity (MNCV) was $3.6 \mathrm{~m} / \mathrm{s}$, distal latency (DL) $40 \mathrm{~ms}$, and compound motor action potentials (cMAPs) $200 \mu \mathrm{V}$; MNCV at the peroneal nerve was $2.4 \mathrm{~m} / \mathrm{s}$. Sensory action potentials (SAPs) were diffusely not evokable. At the age of 7, examination disclosed an ataxic gait with bilateral foot drop, scoliosis, pes cavus, generalised muscle weakness, and wasting prevalent in the legs, areflexia, and distal sensory impairment. Nerve conduction studies 

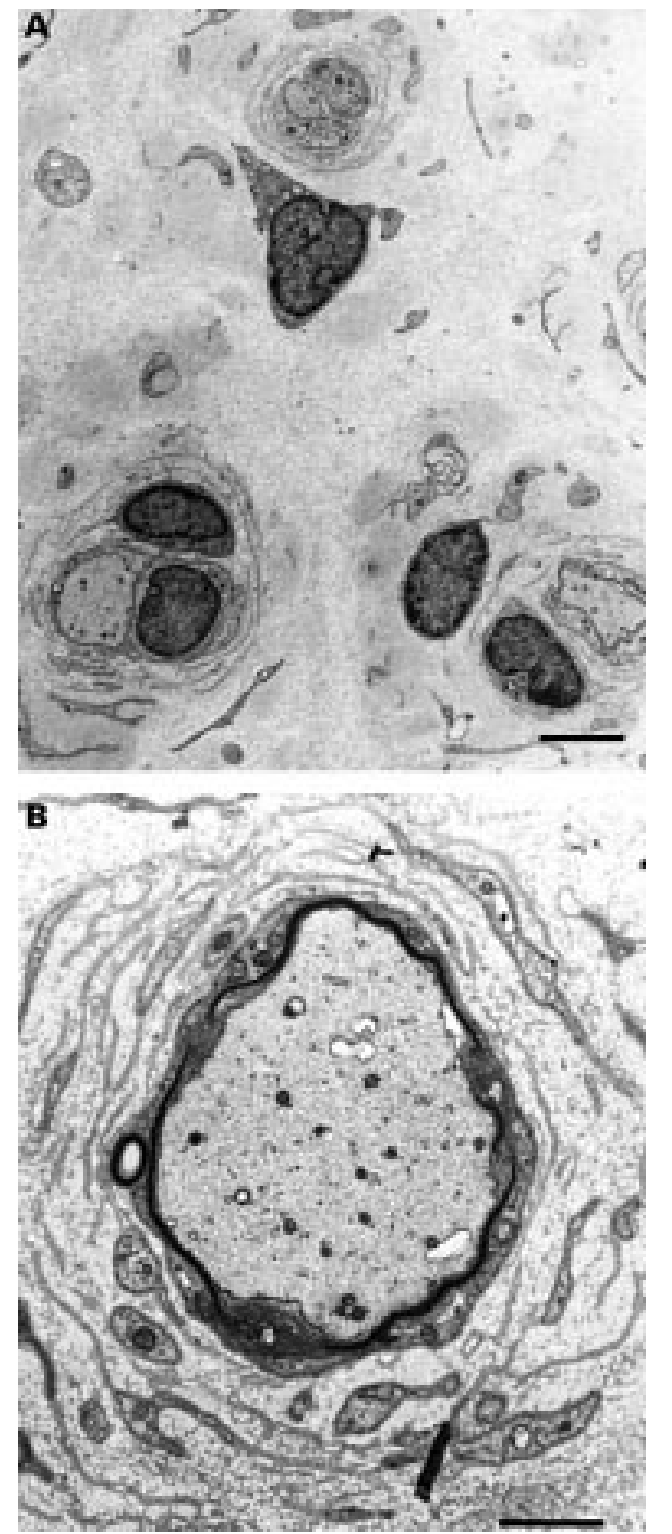

Figure 1 Sural nerve biopsy. Thin section: lead citrate and uranyl acetate stain. (A) low power

electronmicrograph. Three hypomyelinated fibres are surrounded by basal lamina onion bulbs; the endoneurial matrix is covered by an abundant amount of collagen. Bar $=4$ um. (B) A hypomyelinated axon surrounded by a basal lamina onion bulb. Bar $=2 \mu \mathrm{m}$.

showed no modifications compared with the previous examination. Brain stem acoustic evoked potentials (BAEPs) showed bilateral increase of the interpeak latency between waves I and III, indicating an involvement of the peripheral acoustic pathways. Brain MRI was normal.

A left sural nerve biopsy performed at the age of 3 was processed for light and electron microscopy as described elsewhere. ${ }^{5}$ The total transverse fascicular area was increased (1.25 $\mathrm{mm}^{2}$; age matched control $=0.37 \mathrm{~mm}^{2}$ ). Myelinated fibres were markedly decreased (density $=1690$ fibres $/ \mathrm{mm}^{2}$; normal values $=10$ 13000 fibres $/ \mathrm{mm}^{2}$ ). The histogram of the presumptive myelinated fibres was skewed to the left, $94 \%$ of fibres having a diameter smaller than $6 \mu \mathrm{m}$. All fibres had no myelin or extremely thin myelin sheaths and were sur- rounded by Schwann cell processes made of empty basal membranes (fig 1). There was no evidence of active demyelination. The $\mathrm{g}$ ratio (axon diameter $v$ total fibre diameter) was markedly increased (0.92; age matched control=0.73).

Genomic DNA was extracted from blood samples of the proband, parents, and 50 healthy controls. The duplication at chromosome 17p11.2-p12 encompassing the PMP22 gene was ruled out by PFGE analysis as described elsewhere. ${ }^{6}$ The automated direct sequencing of the PMP22 gene and of the myelin protein zero gene (MPZ/P0) was performed as done previously. ${ }^{6}$ In $\mathrm{P} 0$, we did not find any mutation. In PMP22, we detected a heterozygous $\mathrm{T}$ to $\mathrm{C}$ transition at nucleotide (nt) 374 (exon 4) that causes an arginine for cysteine109 substitution in the third transmembrane domain (TM3) (fig 2). Rapid detection of the mutation was performed by restriction fragment length polymorphism analysis because the $\mathrm{T} 374 \mathrm{C}$ transition introduces a $C f o I$ restriction site. Briefly, a 356 base pair (bp) long fragment spanning exon 4 was amplified by polymerase chain reaction (PCR) according to Roa et $a l,{ }^{7}$ and digested with $C f o I$ (New England Biolabs); restriction products were electrophoresed on a $12 \%$ acrylamide gel (acrylamide/bis-acrylamide=19/1). CfoI digestion of the $356 \mathrm{bp}$ fragment generated two bands of 212 and $144 \mathrm{bp}$ in the wild type allele and three bands of $161,144,51 \mathrm{bp}$ in the mutant allele. The T374C transition was absent in the healthy parents as well as in the 50 healthy controls.

\section{Discussion}

In a sporadic patient who met the clinical criteria of DSS, we identified a novel heterozygous Cys109Arg substitution of PMP22. The mutation seemed to be originated de novo because it was absent in the healthy parents. Because the Cys109Arg substitution changes a neutral polar aminoacid into a basic hydrophilic aminoacid and it was absent in 50 healthy controls the mutation is pathogenic. Furthermore, cysteine 109 is likely crucial for the PMP22's structure and function(s) because it is conserved in rat and mouse orthologues, as well as in other growth arrest related molecules belonging to the same family of tetraspan membrane proteins - namely, the human epithelial membrane protein-1 (EMP1) and epithelial membrane protein-2 (EMP-2). ${ }^{8}$

Nerve biopsy was consistent with $\mathrm{CHN}$, disclosing hypomyelination/amyelination and basal laminae onion bulbs in all fibres and no florid demyelination. Because of the pathological picture and the non-progressive evolution, $\mathrm{CHN}$ is envisaged as a defect of myelin formation rather than a disorder of myelin maintenance and stability. ${ }^{4}$

Although current reviews link $\mathrm{CHN}$ with rare mutations of the myelin protein zero (MPZ/P0) gene, which codes the major structural component in the compact myelin of peripheral nerves, or with the early growth response 2 (EGR2) gene, which codes a transcription factor crucial for the Schwann 

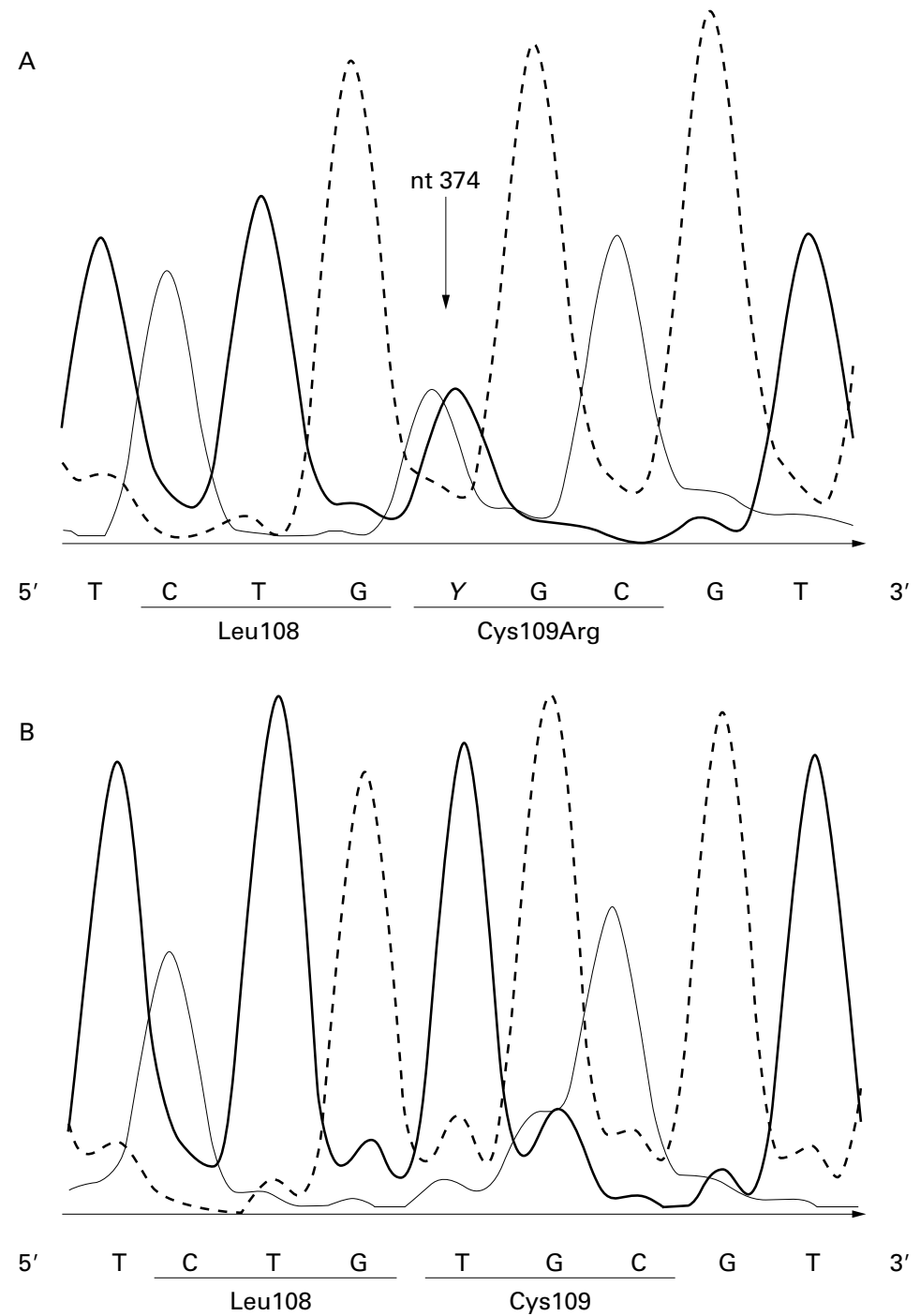

Figure 2 Sense electropherogram encompassing the peripheral myelin protein 22 exon 4, in the patient $(A)$ and in a healthy control $(B) . T=$ bold continuous curve; $C=$ thin continuous curve; $G=$ segmented curve. At nucleotide 374 of the complementary DNA (cDNA), the patient has a $Y$ that indicates a $T$ to $C$ transition (arrow). The mutation is predicted to change a cysteine with an arginine at the aminoacid residue 109 (Cys $109 \mathrm{Arg}$ ).

cell differentiation, ${ }^{2}{ }^{3}$ we think that genetic lesions of PMP22 are a relevant cause of CHN. By reviewing the available pathological phenotypes of missense mutations of PMP22, seven mutations out of 25 (for a review of the mutations see Haites $e t l^{2}$ ) actually seem to be associated with $\mathrm{CHN}$ no matter what the original diagnosis was. The seven mutations included His12Gln (TM1), ${ }^{10}$ Leu16Pro (TM1), ${ }^{11-13}$ Ser72Leu (TM2), ${ }^{14}$ Ser72Trp (TM2), ${ }^{15}$ Ser76Ile (TM2), ${ }^{15}$ Gly100Glu (TM3), ${ }^{16}$ and Leu105Arg (TM3). ${ }^{413}$ For istance, Leu16Pro was identified in three young patients belonging to the same family who were diagnosed as CMT1 because of autosomal dominant inheritance but who really met the clinical, electrophysiological, and pathological criteria of CHN. ${ }^{11-13}$ Furthermore, Vandenberghe et al communicated a patient with CHN who was a genetic compound for a nonsense mutation of PMP22 and the 17p11.2-p12 deletion. ${ }^{2}$ The relation between $\mathrm{CHN}$ and genetic lesions of PMP22 seems even stronger when animal models of inherited neuropathies are consid- ered. The spontaneous murine mutants Trembler-J and Trembler that carry respectively the "human" mutations Leu16Pro (TM1) and Gly150Asp (TM4), also show a severe congenital deficiency of the myelin sheath. ${ }^{1}$

Phenotype to genotype correlations of missense mutations may shed light on the parts that PMP22 plays in peripheral nerves. PMP22 might play a structural, possibly adhesive, function or it might modulate Schwann cell growth and differentiation, as it does in fibroblasts. ${ }^{1}$ Some evidence in vivo and in vitro support the idea that the more common duplication of the entire PMP22 gene alters the Gas3 function and induces an abnormal Schwann cell differentiation. ${ }^{1}$ The pathogenesis of missense mutations is less known. Divergent sites and types of the aminoacid substitutions seem to affect differently the structure and function of PMP22. We recently identified a unique Asp37Val substitution occurring in the first extracellular domain that was associated with a peculiar form of CMT1A characterised by prominent uncompaction of the myelin sheath; this finding suggested that PMP22 has a structural role in the myelin sheath although it is a low-abundant component and has an unusual structure for an adhesive molecule. ${ }^{6}$ On the other hand, the association between CHN and missense mutations distributed in TM1-4 indicates that PMP22 is also involved in Schwann cell differentiation and myelin formation. Thus the pathological phenotypes of missense mutations suggest that PMP22 may have at least a dual function in the peripheral nervous system.

We thank Dr Thomas Pawelzik for editing the manuscript. This work was supported by Telethon-Italy (grant No 1089 to NR) and by the Ministero dell' Universita' e della Ricerca Scientifica (MURST grant No 9806409869).

1 Muller HW. Tetraspan myelin protein PMP22 and demyelinating peripheral neuropathies: new facts and hypotheses. Glia 2000;29:182-5.

2 Haites NE, Nelis E, Van Broeckhoven C. Third workshop of the European CMT consortium: 54th ENMC international workshop on genotype/phenotype correlations in Charcot-Marie-Tooth type 1 and hereditary neuropathy with liability to pressure palsies. Neuromusc Disord 1998;8: 591-603.

3 Keller MP, Chance PF. Inherited neuropathies: from gene to disease. Brain Pathol 1999;9:327-41.

4 Gabreëls-Festen AAWM, Gabreëls FJM, Jennekens FGI, et al. The status of HMSN type III. Neuromusc Disord 1994;4: $63-9$.

5 Simonati A, Fabrizi GM, Pasquinelli A, et al. Congenital hypomyelination neuropathy with Ser72Leu substitution in PMP22. Neuromusc Disord 1999;9:257-61.

6 Fabrizi GM, Cavallaro T, Taioli F, et al. Myelin uncompaction in Charcot-Marie-Tooth neuropathy type $1 \mathrm{~A}$ with a point mutation of peripheral myelin protein 22 . Neurology point mutation of

7 Roa BB, Garcia CA, Suter U, et al. Charcot-Marie-Tooth disease type 1A. Association with a spontaneous point mutation in the PMP22 gene. N Engl f Med 1993;329:96101.

8 Taylor V, Welcher AA, Suter U, et al. Epithelial membrane protein-1, peripheral myelin protein 20 define a novel gene family. F Biol Chem 1995;270:28824-33.

9 Taylor V, Suter U. Epithelial membrane protein-2 and epithelial membrane protein-3: two novel members of the peripheral myelin protein 22 gene family. Gene 1996;175: 115-20.

10 Valentijn LJ, Ouvrier RA, Van Den Bosch NHA, et al. Dejerine-Sottas neuropathy is associated with a de novo PMP22 mutation. Hum Mut 1995;5:76-80.

11 Valentijn LJ, Baas F, Wolterman RA, et al. Identical point mutations of PMP-22 in Trembler-J mouse and CharcotMarie-Tooth disease type1A. Nat Gen 1992;2:288-291.

12 Gabreëls-Festen AAWM, Joosten EMG, Gabreëls FJM, et al. Early morphological features in dominantly inherited demyelinating motor and sensory neuropathy (HMSN type I). $\mathcal{F}$ Neurol Sci 1992;107:145-54 
13 Gabreëls-Festen AAWM, Bolhuis PA, Hoogendijk JE, et al. Charcot-Marie-Tooth disease type 1A: morphological phenotype of the $17 \mathrm{p}$ duplication versus PMP22 poin mutations. Acta Neuropathol 1995;90:645-9.

14 Roa BB, Dyck PJ, Marks HG, et al. Dejerine-Sottas syndrome associated with point mutation in the peripheral myelin protein 22 (PMP22) gene. Nat Genet 1993;5:269-72
15 Tyson J, Ellis D, Fairbrother U, King RHM, et al. Hereditary demyelinating neuropathy of infancy. A genetically com1997;120:47-63.

16 Marques W, Thomas PK, Sweeney MG, et al. DejerineSottas neuropathy and PMP22 point mutations: a new base pair substitution and a possible hot spot on Ser72. Ann Neurol 1998;43:680-3.

\section{NEUROLOGICAL STAMP}

\section{Wilhelm Conrad Von Röntgen (1845-1923)}

Röntgen's parents, a German father and Dutch mother, were cousins. He was born in Lennep in Germany, but his family moved to Holland when he was 3 years old.

At the age of 17 he was enrolled as a student in the Technical School in Utrecht. He was expelled through no fault of his own without matriculating. Because of this he was unable to sit university examinations. One of his classmates is said to have drawn a caricature of a teacher and failed to own up. Röntgen seems to have been a troublemaker in class and probably the obvious person for the teacher to blame. All his school reports showed excellent marks, although, ironically, with the exception of physics.

Röntgen qualified at the age of 23 as a mechanical engineer from the Polytecnikum in Zurich. His experimental attitude and unusual qualities were noticed by August Kundt, Professor of Physics in Zurich, who gave him a

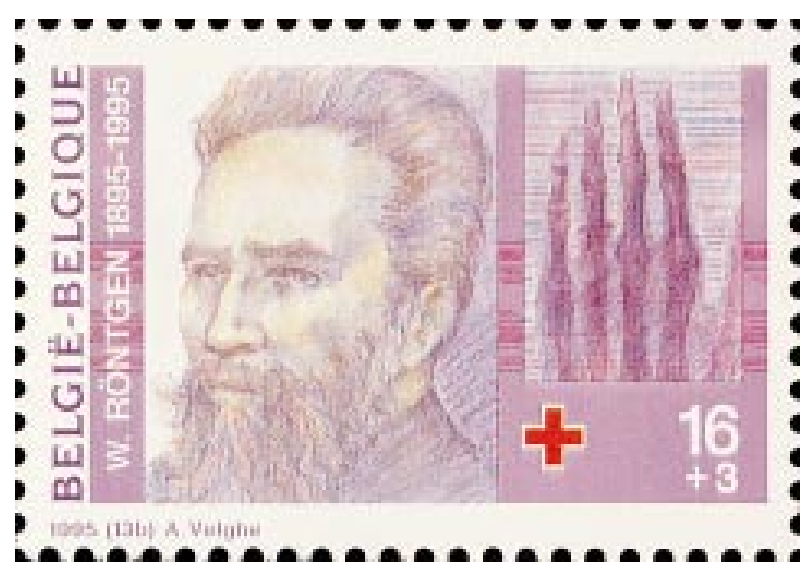

place in his laboratory. In 1869 he received his PhD. In 1870 Kundt became Professor of Physics in Würzburg in Bavaria. He wanted Röntgen, who was his assistant, to become a member of the faculty but the university refused because he lacked the requisite training in classical languages. In 1888 Röntgen became Professor of Physics at Würzburg. Before that there were professorships in other institutions. It is for discovery of $x$ rays that he is most remembered and for which he received several honours including the first ever Nobel Prize for physics in 1901. He submitted his manuscript Eine neue Art von Strahlen-A new kind of ray (Vorläufige Mittheilung) - (preliminary communication) by von Dr W Röntgen to the Würzburg Physical Medical Society for publication in Sitzungsberichte der Physikalisch-Medizinischem Gesellschaft (Proceedings of the Society for Physical Medicine) on 28 December 1895. It was of great satisfaction to the Swedish Academy of Science that such an eminent achievement could be rewarded at the first distribution. The announcement to the world of one of the most dramatic events in the history of science, made on 6 January 1896, was greeted with universal enthusiasm. The first $x$ ray photograph was of his wife's hand. In the same year that he received the Nobel Prize Röntgen was appointed Professor of Physics in Munich. He continued to work at the University until 1920. After his wife died he lived in solitude and poverty amid the general economic collapse of Germany after the first world war.

There were many stamps issued in honour of Röntgen in 1995, a century after the discovery of $x$ rays. Reproduced is a stamp from Belgium commemorating the event. This shows Wilhelm Röntgen and the hand of his wife Bertha. Her ring can be seen on the ring finger (Stanley Gibbons 3279, Scott B1124).

L F HAAS 